\title{
Micrococcaceae from the urinary tract in pregnancy
}

\author{
A. P. ROBERTS
}

From the Institute of Obstetrics and Gynaecology, Queen Charlotte's Hospital, London

SYNOPSIS Gram-positive, catalase-positive cocci (Micrococcaceae) have been obtained from the bladder by suprapubic aspiration of urine in antenatal and postnatal patients. These bacteria have been compared with similar organisms isolated from midstream specimens of urine when the suprapubic specimen was sterile.

Fourteen $(70 \%)$ of 20 organisms isolated from the bladder were micrococci and six (30\%) were staphylococci. In contrast $17(85 \%)$ of 20 similar organisms contaminating midstream urine specimens were staphylococci and only three $(15 \%)$ were micrococci.

Reports of urinary tract infections due to coagulasenegative staphylococci (Pereira, 1962; Mitchell, 1964) have added to the difficulty of distinguishing genuine bacteriuria from contamination in midstream specimens of urine. However, in screening antenatal patients, Kincaid-Smith, Bullen, Mills, Fussell, Huston, and Goon (1964) excluded such organisms since repeat specimens after vulval cleansing showed that their presence was almost always due to contamination. Smith (1965) also doubted whether these organisms were urinary pathogens. Fairley, Bond, Adey, Habersberger, and McCredie (1966) have clearly demonstrated in a small number of cases that organisms which they have identified as Staphy-

Received for publication 24 February 1967. lococcus albus may be present in bladder and ureteric urine.

The purpose of the present investigation was to attempt to isolate Gram-positive, catalase-positive cocci (Micrococcaceae) from the bladder by suprapubic aspiration of urine and to compare any such organisms with those obtained from midstream specimens where the suprapubic urine was sterile.

\section{PATIENTS AND METHODS}

Routine screening of midstream specimens of urine from antenatal and postnatal patients was carried out. If any specimen was found to contain more than 10,000 organisms per millilitre and included Gram-positive, catalase-positive cocci a further specimen of urine was

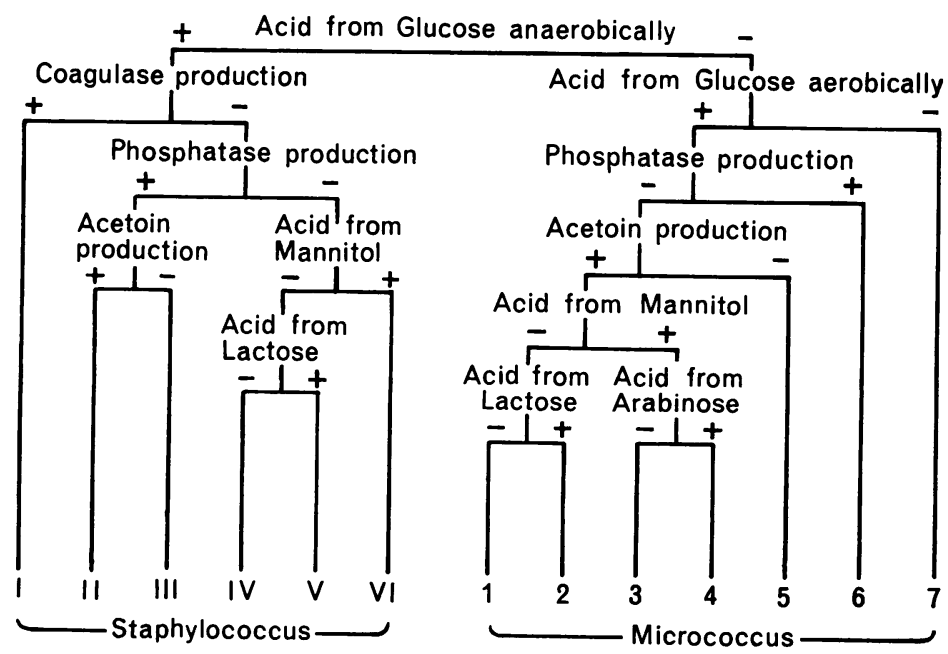

FIG. 1. Key for grouping

the cultures. 
collected by suprapubic aspiration (Beard, McCoy, Newton, and Clayton, 1965). A second midstream specimen was obtained immediately after the suprapubic urine. All specimens were refrigerated at $4^{\circ} \mathrm{C}$. within five minutes of collection.

The specimens were cultured initially on blood agar. Isolated colonies were plated three times on nutrient agar for purity.

The cultures were grouped using the key shown in Figure 1. The tests used to characterize each organism are also shown in Fig. 1 and were carried out as described by Baird-Parker (1963) except that human plasma was used for the coagulase test. All tests were performed at least twice on each culture with an interval of two to three months between each series.

\section{RESULTS}

Gram-positive, catalase-positive cocci were isolated from suprapubic urine specimens in 20 patients (bladder organisms). Similar organisms were obtained from midstream urines where the suprapubic urine was sterile in a further group of 20 patients (contaminants). The distribution of organisms within these groups is shown in Table I. Of the bladder organisms, 14 were micrococci and six were staphylococci. Three of the contaminant organisms were micrococci and 17 staphylococci. This difference in distribution is statistically highly significant ( $\chi^{2}$ with Yates correction $\left.=10.23 \mathrm{P}<0.005\right)$.

\section{TABLE I}

NUMBERS OF PATIENTS IN RELATION TO THE DISTRIBUTION OF ORGANISMS

\begin{tabular}{lcrrr} 
& $\begin{array}{l}\text { Bladder Organisms } \\
\text { in 20 Patients }\end{array}$ & $\begin{array}{l}\text { Contaminants } \\
\text { in 20 Patients }\end{array}$ \\
\hline Micrococcus (total) & $14(70 \%)$ & $3(15 \%)$ & 1 \\
Micrococcus (subgroup 2) & & 2 & & 1 \\
Micrococcus (subgroup 3) & 11 & & 1 \\
Micrococcus (subgroup 5) & 0 & $17(85 \%)$ & 0 \\
Micrococcus (Subgroup 7) & $6(30 \%)$ & 1 & & 13 \\
Staphylococcus (total) & & 6 & & 4 \\
Staphylococcus (subgroup II) & & 0 & &
\end{tabular}

One patient had acute pyelonephritis when the only organisms isolated from the suprapubic specimen were micrococci (subgroup 3). Fourteen of the infected patients received treatment immediately the result of the suprapubic specimen was known, but of six patients who were left untreated for six weeks, in three the infection resolved spontaneously.

Coagulase-positive staphylococci were never obtained from suprapubic urine specimens and the few midstream urines found to contain these organisms have not been included in this study.

When the tests were repeated on the cultures after an interval of two to three months the results were the same.

\section{DISCUSSION}

The distribution between the genera Staphylococcus and Micrococcus of the contaminant organisms in the present study is similar to that of coagulasenegative, Gram-positive, catalase-positive $\operatorname{cocci} \vec{\omega}$ from human sources reported by Baird-Parker? (1965). The predominance of micrococci $(70 \%)$ ? among the bladder organisms reported here is in 0 marked contrast to both these distributions. The $A$ majority of staphylococci were placed in subgroup II. This is in agreement with the findings of BairdParker (1965) but again the predominance of sub-으 group 3 among the micrococci is unexpected. Some factor in the urinary tract clearly acts selectively in $\subseteq$ favour of micrococci and in particular of subgroup 3.

The separation of Gram-positive, catalase-positive $\bar{\varnothing}$ cocci into staphylococci and micrococci and into. $v$ subgroups of each (Baird-Parker 1963) is not normally carried out in hospital laboratories. In these circumstances all the organisms isolated in this study would be reported as coagulase-negative staphylococci. The present work and that of Fairley $\frac{\mathbb{Q}}{\square}$ et al. (1966) has shown that reports of such organ- $\vec{F}$ isms in midstream specimens of urine cannot be을 dismissed as contamination.

As with other urinary tract pathogens infections due to Micrococcaceae may resolve spontaneously, persist asymptomatically, or result in acute pyelonephritis.

I would like to thank Professor S. G. Clayton for allowing me to study his patients and Dr. R. W. Beard for advice 3 and encouragement. I am also indebted to Miss Cynthia ${ }_{O}$ Knight for technical assistance and the resident medical officers, sisters, and nurses of 4th East Ward for collecting $\frac{D}{0}$ the specimens.

\section{REFERENCES}

Baird-Parker, A. C. (1963). J. gen. Microbiol., 30409.

- (1965). Ibid., 38, 363.

Beard, R. W., McCoy, D. R., Newton, J. R., and Clayton, S. G. (1965) Lancet, 2, 610.

Fairley, K. F., Bond, A. G., Adey, F. D., Habersberger, P., and McCredie, M. (1966). Ibid., 1, 939.

Kincaid-Smith, P., Bullen, M., Mills, J., Fussell, U., Huston, N., and Goon, F. (1964). Ibid., $2,61$.

Mitchell, R. G. (1964). J. clin. Path., 17, 105.

Pereira, A. T. (1962). Ibid., 15, 252.

Smith, L. G. (1965). Lancet, 1, 221. 